\title{
Automated intermittent epidural boluses improve analgesia induced by intrathecal fentanyl during labour
}

\author{
[L'administration automatisée de bolus intermittents améliore l'analgésie induite \\ par du fentanyl intrathécal pendant le travail]
}

Sebastian M.H. Chua mmed, ${ }^{*}$ Alex T.H. Sia mmed $\dagger$

Purpose: We compared the efficacy of epidural continual intermittent boluses (CIB) with a continuous epidural infusion (CEI) in prolonging labour analgesia induced by the combined spinal epidural (CSE) technique.

Methods: CSE was instituted in 42 nulliparous parturients at the L3 to 4 level with intrathecal (IT) fentanyl $25 \mu \mathrm{g}$ followed by an epidural test dose of $3 \mathrm{~mL}$ of $1.5 \%$ lidocaine. These parturients were then randomly assigned to receive either epidural CIB $(n=21)$ or CEI $\left(n=21\right.$ ) with $0.1 \%$ ropivacaine and fentanyl $2 \mu \mathrm{g} \cdot \mathrm{mL}^{-1}$. For the $\mathrm{CIB}, 5 \mathrm{~mL}$ boluses were given hourly, with the first bolus $30 \mathrm{~min}$ postinduction. CEl at the rate of $5 \mathrm{~mL} \cdot \mathrm{hr}^{-1}$ was initiated in the minute after CSE. The duration of analgesia, pain score, degree of sensorimotor block were compared.

Results: From Kaplan Meier survival analysis, the duration of analgesia was significantly longer in CIB (mean survival time $239 \pm$ SD 24 min vs $181 \pm 17, P<0.05$ using log rank test). During the first three hours postblock, the median sensory block to cold was higher in $\mathrm{CIB}(P<0.05$, Mann $\cup$ Whitney test $)$ but no difference in blood pressure was detected $[P>0.05$, repeated measure analysis of variance (RMANOVA)]. The serial pain scores were lower in the $\mathrm{CIB}(P<0.05$, RMANOVA $)$.

Conclusion: $\mathrm{CIB}$ prolonged the duration and improved the quality of analgesia. CIB could have resulted in an improved spread of analgesics in the epidural space or encouraged a direct passage of infusate into the IT space. This could have also rendered a higher sensory block to cold in the CIB group. CIB is a good alternative to CEl for the maintenance of epidural analgesia after CSE.
Objectif : Comparer l'efficacité de bolus périduraux intermittents administrés en continu (BIC) avec la perfusion péridurale continue (PPC) comme analgésie prolongée pendant le travail induite selon une technique rachidienne péridurale combinée (RPC).

Méthode : L'analgésie RPC a été installée chez 42 parturientes nullipares au niveau L3 à 4 avec $25 \mu \mathrm{g}$ de fentanyl intrathécal (IT) suivi d'une dose test péridurale de $3 \mathrm{~mL}$ de lidocaïne à 1,5\%. Les patientes ont été randomisées pour recevoir soit des BIC périduraux ( $n$ $=21)$, soit une PPC $(n=21)$ avec ropivacaïne à $0,1 \%$ et $2 \mu \mathrm{g} \cdot \mathrm{mL}^{-1}$ de fentanyl. Dans le cas des BIC, des bolus de $5 \mathrm{~mL}$ à chaque heure ont été donnés, dont le premier 30 min après l'induction. La PPC a débuté une minute après la $R P C$ à raison de $5 \mathrm{~mL} \cdot h^{-1}$. La durée de l'analgésie, les scores de douleur, le degré de bloc sensorimoteur ont été comparés.

Résultats : À partir de l'analyse de survie de Kaplan Meier, on a trouvé une analgésie significativement plus longue avec les BIC (temps de survie moyen de $239 \pm$ l'écart type 24 min vs $181 \pm 17, P<0,05$ avec le test du logrank). Pendant les trois premières heures suivant le bloc, le bloc sensitif moyen au froid a été plus élevé avec les $B I C(P<$ 0,05 , test $U$ de Mann Whitney) mais aucune différence de tension artérielle n'a été détectée $[P>0,05$, analyse répétée de la variance à plusieurs variables (repeated measure analysis of variance RMANO$V A)]$. Les scores de douleur en série ont été plus bas avec les BIC ( $P$ $<0,05$, RMANOVA).

Conclusion : Les BIC ont prolongé la durée et amélioré la qualité de l'analgésie. Les BIC peuvent améliorer la diffusion de l'analgésie dans l'espace péridural ou favoriser le passage direct de la perfusion dans l'espace IT. Cette technique peut aussi avoir augmenté le bloc sensitif au froid. Les BIC sont un bon équivalent de la PPC pour le maintien de l'analgésie péridurale après la RPC.

From the Departments of Anaesthesia, Singapore General Hospital, ${ }^{*}$ and the KK Women and Children's Hospital, $†$ Singapore. Address correspondence to: Dr. Sebastian M.H. Chua, Department of Anaesthesia, Singapore General Hospital, Outram Rd, Singapore 169608. Phone: 65-6321-4220; Fax: 65-6224-1792; E-mail: sebnjess@singnet.com.sg Accepted for publication November 27, 2003.

Revision accepted March 26, 2004. 
$\mathrm{T}$

HE combined spinal epidural (CSE) technique has been used widely to induce analgesia during labour. However, the maintenance of epidural analgesia after intrathecal (IT) induction is a subject of debate. Although the use of a continuous epidural infusion (CEI) before the loss of spinal analgesia is gaining popularity, ${ }^{1}$ it is unknown if employing a regimen of automated continual intermittent boluses (CIB) could improve the analgesic function of the epidural catheter. Experimentally, the spread of infusate from a multi-orificed catheter had been found to be more extensive if regular boluses were used instead of a continuous infusion despite a similar rate of discharge. ${ }^{2}$

In this study, we aimed to compare the efficacy of CEI with CIB in the maintenance of epidural analgesia after the induction of CSE during early labour. We hypothesized that the potentially improved spread of analgesic solution in the epidural space during CIB could, to a greater degree than CEI, prolong the duration of analgesia rendered by the initial IT component of CSE.

\section{Methods}

With the approval of the Hospital's Ethics Committee, 42 ASA physical status I nulliparous women in early spontaneous labour pain with at least one contraction in five minutes who had requested neuraxial block were recruited in this randomized double-blinded controlled trial. Exclusion criteria included: multiparity, pain score of $<30$ on a 0 to 100 visual analogue scale $($ VAS; $0=$ no pain, $100=$ worst pain imaginable), cervical dilatation $>5 \mathrm{~cm}$, premature labour ( $<36$ weeks gestation), suspected macrosomia, non-cephalic presentation, pre-eclampsia, gestational diabetes mellitus and the presence of contraindications to neuraxial block such as coagulopathy, sepsis and hemorrhage.

After obtaining written informed consent, $0.5 \mathrm{~L} \mathrm{lac}$ tated Ringer's solution was infused $i v$ before CSE and a preblock pain score on the VAS was taken. Preblock systolic blood pressure (SBP) was measured non-invasively on the right arm (DINAMAP, Critikon, Tampa, FL, USA) with the parturients supine but with a left lateral tilt effected by placing a wedge under the right hip. The parturients were then randomly assigned by the blind opaque envelope technique to receive either epidural CIB $(n=21)$ or CEI $(n=21)$. Prior to CSE, all fetal heart rate tracings were confirmed to be reactive by the attending obstetrician. Continuous fetal heart tracings were then monitored closely for the first 30 min postblock.

CSE was instituted in the sitting position. The epidural space was identified at the L3 or L4 level in the midline with an 18-G Tuohy needle by using the loss of resistance to air technique, followed by dural puncture with a 27-G pencil-point needle through the Tuohy needle (Espocan, B.Braun, Melsungen, Germany). All the blocks were performed by the principal investigator (S.M.H.C.). After ensuring a free flow of cerebrospinal fluid, fentanyl $25 \mu \mathrm{g}$ was injected intrathecally and the spinal needle removed. A multi-orificed 20-G epidural catheter was then inserted and a length of $3 \mathrm{~cm}$ was left in the epidural space. After confirming the absence of blood on aspiration, ${ }^{3}$ a 'test dose' of $3 \mathrm{~mL}$ of $1.5 \%$ lidocaine (Xylocaine, Astrazeneca, Sodertalje, Sweden) was injected into the catheter. If blood was detected on aspirating the catheter, the epidural catheter would be removed and resited. The parturient would be excluded from the study and the sealed envelope would be made available for a second randomization.

The parturients were then positioned supine with a left lateral tilt. Motor block was assessed every five minutes for the first half-hour postblock and every hour after CSE. The modified Bromage scale $[0=$ no impairment; $l=$ unable to raise the extended leg but able to move knees and feet; 2 = unable to raise extended leg as well as flex knees, able to move foot; 3 = not able to flex ankle, feet or knees (complete block)] was used to assess lower limb motor block. Similarly, SBP was recorded every five minutes for the first half-hour postblock and every $15 \mathrm{~min}$ subsequently. The lowest SBP at the end of every hour after time 0 was recorded. In the presence of motor block to a degree greater than Bromage 1 and/or a reduction of SBP $\geq 30 \%$ from the baseline value during the first ten minutes postblock, the subject would be withdrawn from the study because of possible subdural or subarachnoid catheter placement.

The time of completion of the injection of the 'test dose' was defined as time 0 . All the parturients received a solution of ropivacaine $0.1 \%$ plus fentanyl 2 $\mu \mathrm{g} \cdot \mathrm{mL}^{-1}$ for the maintenance of epidural analgesia. The Graseby 9200 pump (SIMS Graseby, Watford, United Kingdom) was employed for CIB. The initial $5 \mathrm{~mL}$ bolus was administered $30 \mathrm{~min}$ after time 0 , followed by $5 \mathrm{~mL}$ boluses every hour thereafter. As the highest rate of delivery afforded by the pump was 100 $\mathrm{mL} \cdot \mathrm{hr}^{-1}$, each epidural bolus was delivered over three minutes. For CEI, a rate of $5 \mathrm{~mL} \cdot \mathrm{hr}^{-1}$ was initiated one minute after time 0 by using a Terumo syringe pump (Terumo Corporation, Tokyo, Japan).

For half an hour after time 0, VAS was taken every ten minutes and then every hour after the block. The level of sensory block to cold was assessed using ice ten minutes after time 0 and hourly after CSE. All data 
TABLE Maternal demographic profile and preblock values

\begin{tabular}{lll}
\hline & $\begin{array}{l}\text { Group CIB } \\
(n=21)\end{array}$ & $\begin{array}{l}\text { Group CEI } \\
(n=21)\end{array}$ \\
\hline Maternal height $(\mathrm{cm})$ & $155.7(6.8)$ & $158.9(5.1)$ \\
Maternal weight $(\mathrm{kg})$ & $65.3(11.8)$ & $69.9(12.2)$ \\
Baseline systolic blood pressure $(\mathrm{mmHg})$ & $122.6(14.4)$ & $123.9(12.2)$ \\
Baseline pain score $(0-100$ VAS) & $65(30-100)$ & $70(30-100)$ \\
Cervical dilatation at time of block $(\mathrm{cm})$ & $3(2-4)$ & $3(2-4)$ \\
Preblock oxytocin use $(n)$ & 9 & 8 \\
\hline
\end{tabular}

Values for maternal height, weight and blood pressure are expressed as mean (SD). Pain scores and cervical dilatation are expressed as median (maximum - minimum). The actual number of parturients who had had preblock oxytocin is shown. No significant difference was found between the two groups. CIB = continual intermittent boluses; CEI = continuous epidural infusion; VAS $=$ visual analogue scale.

were collected by an anesthesiologist who was not involved in instituting the block.

The time when patients requested supplemental analgesia while on either epidural maintenance regimen was defined as time END. Duration of analgesia was the difference between time END and time 0 . Parturients who delivered prior to the loss of analgesia were excluded at the time of delivery but accounted for in the Kaplan Meier survival analysis for duration of analgesia. If the VAS was greater than 10 , $20 \mathrm{~min}$ after time 0 , the block would be labelled as 'ineffective' and the parturient would be excluded from further analysis. Pain 'rescue' medication in the form of $5 \mathrm{~mL}$ aliquots of ropivacaine $0.2 \%$ would then be given epidurally followed by a continuous infusion of $0.1 \%$ ropivacaine plus $2 \mu \mathrm{g} \cdot \mathrm{mL}^{-1}$ fentanyl at the rate of $10 \mathrm{~mL} \cdot \mathrm{hr}^{-1}$.

The sample size was computed to detect a 30 -min difference $(\alpha=0.05, \beta=0.2)$ in the duration of analgesia. The following tests were used for the comparison of data between the two groups: log rank test for survival analysis of the duration of analgesia, Student's $t$ test for parametric data, Mann U Whitney test for non-parametric data; Fisher's exact test for proportions and repeated measures ANOVA for pain score and lowest blood pressure. Results are expressed as mean (with standard deviation) or median (with range). A value of $P<0.05$ was considered statistically significant.

\section{Results}

There were no significant differences in patient preblock characteristics between the two groups. (Table). All parturients completed the study and none was excluded due to the possible subdural/subarachnoid

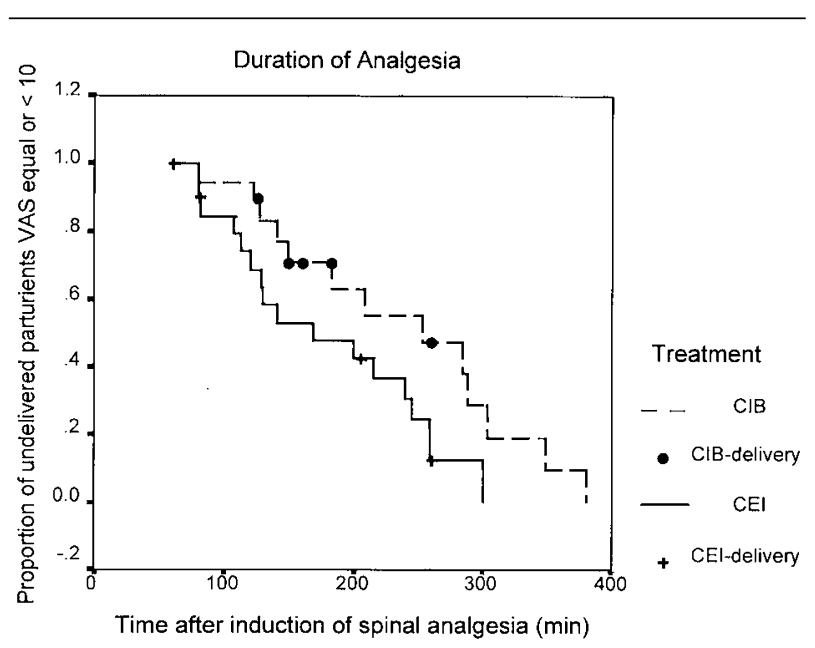

FIGURE 1 Proportion of continual intermittent boluses (CIB) and continuous epidural infusion (CEI) patients with effective analgesia $v s$ time after intrathecal injection (patients delivering prior to loss of analgesia are included up to the time of delivery). $P<0.05$ between the two groups.

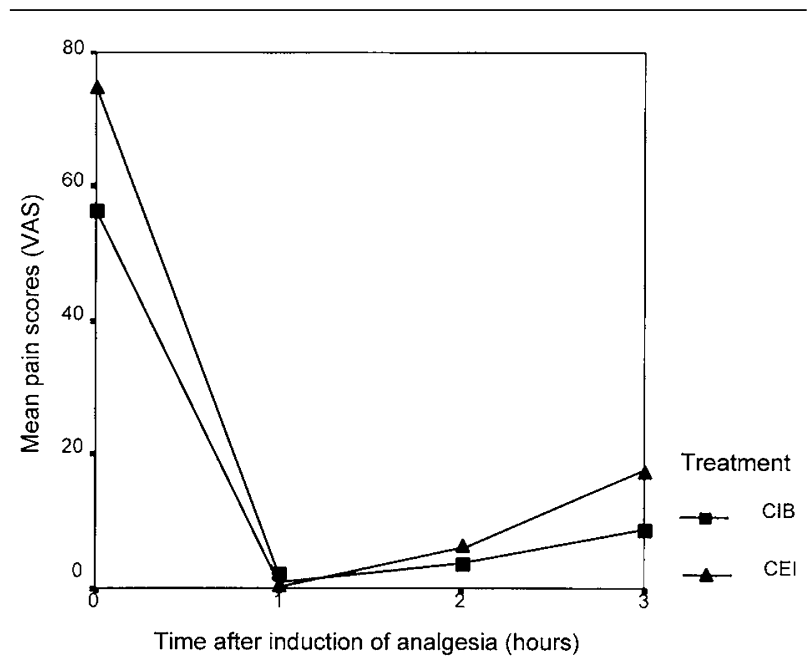

FIGURE 2 Mean pain scores $v s$ time after spinal analgesia. VAS = visual analogue score. $P<0.05$ between the two groups.

placement of the epidural catheter. There were also no 'ineffective' blocks. There were no new ominous or non-reactive fetal heart rate changes requiring an emergent delivery in the first 30 min postblock.

The duration of analgesia in CIB (mean survival time $239 \pm 24 \mathrm{~min}$ ) was significantly longer compared to CEI (mean survival time $181 \pm 17 \mathrm{~min}, P<0.05$ using log rank test; Figure 1). Four parturients in CIB 


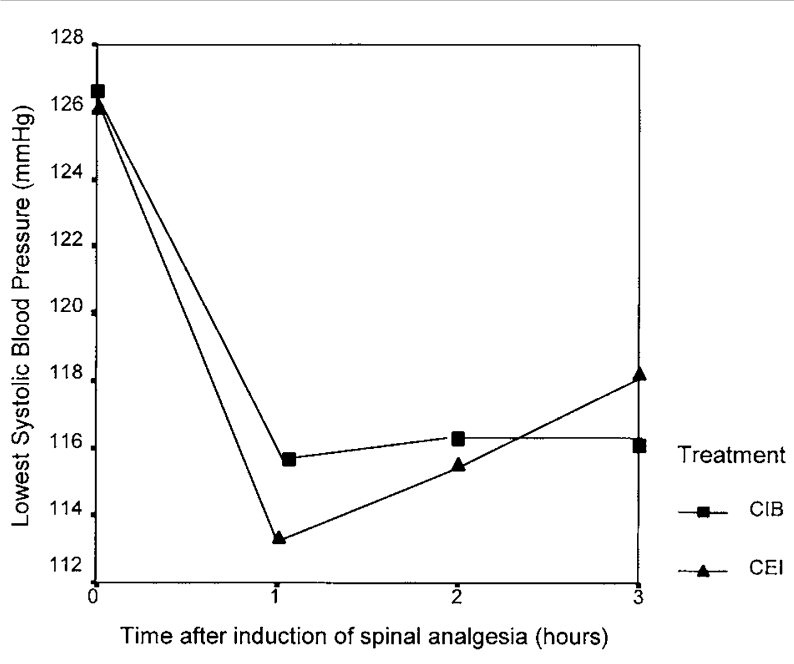

FIGURE 3 Lowest systolic blood pressure (mean) vs time after spinal analgesia. No significant difference between the two groups.

and five in CEI delivered without the need for supplemental analgesia $(P>0.05$, Fisher's exact test). The CIB group displayed a significantly lower pain score than CEI $(P<0.05$, repeated measure ANOVA) during the first three hours (Figure 2 ). The hourly consumption of epidural bupivacaine + fentanyl solution prior to the loss of analgesia or delivery was similar between the two groups (mean $5.2 \mathrm{~mL} \cdot \mathrm{hr}^{-1} \pm$ SD 0.6 for CIB vs $5.0 \pm 0.5$ for CEI, $P>0.05$ ).

The most cephalad sensory block to cold assessed during the first three hours after CSE was higher in CIB than CEI (median T2 (range Tl-T8) vs T4 (Tl-Tl1), $P<0.05)$. However, serial SBP were indistinguishable between the two groups during this same period of time $(P>0.05$, Figure 3$)$. None of the parturients had a decline of SBP $>20 \%$ of the preblock value prior to time END. Two parturients, one in each group had some lower limb motor block, not greater than Bromage 1.

\section{Discussion}

The practice of starting an epidural infusion while the IT component of a CSE technique is still effective has been shown to prolong the duration of spinal analgesia in labouring women. ${ }^{4}$ Our study shows that CIB prolonged the duration of labour analgesia induced by CSE to a greater degree than CEI. Parturients in the CIB group had lower pain scores and a higher sensory block than CEI.
Experimentally, a greater spread of infusate from a multi-orificed catheter was found when intermittent boluses were used instead of a continuous infusion, despite a similar rate of infusion. ${ }^{2}$ Moreover, when a continuous infusion was used, there was practically no flow through the distal hole, whereas when intermittent bolusing was used, the infusate flowed out from all the holes. Hogan also suggested that the use of intermittent boluses could produce a more uniform epidural block than a continuous infusion due to the difference of injectate pressure, based on his study in human cadavers. ${ }^{5}$

In another study on epidural analgesia during labour, intermittent bolusing was also found to reduce analgesic requirements and the need for additional top-up boluses. ${ }^{6}$ The authors attributed this to a higher driving pressure associated with intermittent boluses. In that study, a common $10.5 \mathrm{~mL} \cdot \mathrm{hr}^{-1}$ basal infusion/bolusing rate was used. We suggest that the higher sensory block and longer duration of analgesia in the CIB group results from the improved spread of analgesics in the epidural space, secondary to a higher driving pressure. However, we are unable to substantiate this, as we did not measure changes in epidural pressure with either regimen used in our study.

We induced analgesia by CSE. Continual bolusing, with its attendant greater driving pressure, could also have an arguably more profound epidural volume expansion (EVE) effect than a slow continuous infusion. A rapid injection of saline into the epidural space after subrachnoid administration of local anesthetics has been found to promote the cephalad spread of sensory block, a technique called 'EVE'. The contribution of a greater EVE effect from continual bolusing in the first hours after CSE induction could have played a role to enhance the sensory block and the quality of analgesia.

Shortly after CSE induction by the IT injection of local anesthetics, the epidural injection of local anesthetics has been found to enhance cephalad spread of the block more rapidly than the epidural injection of the same volume of saline. ${ }^{8}$ Similarly, a bolus of local anesthetic through a catheter in the epidural space has been found to result in a greater degree of sensorimotor block in the event of a prior intentional dural puncture during CSE. ${ }^{9}$ This has been attributed to some degree of direct migration of analgesics into the subarachnoid space through the dural rent post CSE. Intuitively, the higher driving pressure associated with continual bolusing could, potentially, facilitate the magnitude of this flux. This could also have been partially responsible for the higher sensory block in CIB in our study. More research is required in this regard. 
The low concentration and rate of epidural infusion/boluses used may have been responsible for the overall lack of change of SBP and the low incidence of motor block (only 2/42 parturients had any degree of lower limb motor block) in our study. The use of low dose epidural infusion/boluses resulted in a majority of parturients requiring supplemental analgesia before reaching the second stage of labour. The use of higher doses of infusion/boluses could have prolonged the duration of analgesia induced by $\mathrm{CSE},{ }^{4}$ albeit at the expense of a higher number of parturients with greater sensory and motor blocks. ${ }^{6}$ Even though the sensory block reached a high dermatomal level, it did not ascend during the study and there was no corresponding motor impairment or respiratory depression. The extent of sensory block could have been confounded by the action of IT fentanyl on opioid receptors. ${ }^{10}$

In conclusion, in labouring parturients, the use of epidural CIB was more effective than CEI in prolonging analgesia induced by IT fentanyl. This was associated with lower pain scores and a higher sensory block in CIB. CIB appears to be a good alternative to CEI for the maintenance of labour epidural analgesia.

\section{References}

1 Gaiser RR, Lewin SB, Cheek TG, Gutsche BB. Effects of immediately initiating an epidural infusion in the combined spinal and epidural technique in nulliparous parturients. Reg Anesth Pain Med 2000; 25: 223-7.

2 Kaynar AM, Shankar KB. Epidural infusion: continuous or bolus? (Letter). Anesth Analg 1999; 89: 534.

3 Norris MC, Ferrenbach D, Dalman H, et al. Does epinephrine improve the diagnostic accuracy of aspiration during labor epidural analgesia? Anesth Analg 1999; 88: 1073-6.

4 Beilin Y, Nair A, Arnold I, et al. A comparison of epidural infusions in combined spinal/ epidural technique for labor analgesia. Anesth Analg 2002; 94 : 927-32.

5 Hogan Q. Distribution of solution in the epidural space: examination by cryomicrotome section. Reg Anesth Pain Med 2002; 27: 150-6.

6 Bhavani-Shankar K, Malov S, Hurley R, Datta S. Do rapidly administered intermittent epidural boluses provide better labor analgesia? Anesthesiology 2000; 93(Suppl): Al071.

7 Picard J, Crowhurst JA, Plaat F. Failure to achieve consistent anesthesia could be attributed to technique (Letter). Reg Anesth Pain Med 2001; 26: 588.

8 Stienstra R, Dilrosun-Albadi BZ, Dahan A, van Kleef $J W$, Th Veering B, Burm $A G$. The epidural "top-up" in combined spinal-epidural anesthesia: the effect of volume versus dose. Anesth Analg 1999; 88: 810-4.
9 Leighton BL, Arkoosh VA, Huffnagle S, Huffnagle HJ, Kinsella SM, Norris MC. The dermatomal spread of epidural bupivacaine with and without prior intrathecal sufentanil. Anesth Analg 1996; 83: 526-9.

10 Riley ET, Ratner EF, Cohen SE. Intrathecal sufentanil for labor analgesia: do sensory changes predict better analgesia and greater hypotension? Anesth Analg 1997; 84: 346-51. 